\title{
Preliminary Assessment of Neotropical Mammal DNA Barcodes: An Underestimation of Biodiversity
}

\author{
Burton K. Lim* \\ Department of Natural History, Royal Ontario Museum, 100 Queen's Park, Toronto, Ontario M5S 2C6, Canada
}

\begin{abstract}
There are almost 1,700 species of mammals occurring in the Neotropical region broadly defined as including Mexico, Central America, the Caribbean Islands, and South America. The Barcode of Life Data (BOLD) Systems established an institutional collaboration with the Royal Ontario Museum (ROM) beginning in 2005 to DNA barcode the mammal tissue collections for the cytochrome oxidase subunit I (COI) gene region. To date, over 14,500 vouchered specimens have been sequenced representing nearly 19\% (317 species) of the mammalian diversity in the Neotropics. This includes 11 of the 15 orders found in the Neotropics with the 4 missing orders representing less than 20 species. Almost half of the bat species (167 of 345) have been barcoded but only 3\% (4 of 129) of the primate species have been done. Rodents are the most diverse order in the Neotropics, of which 12\% of the species have been barcoded (106 of 898 ). In terms of geographic coverage, Middle America is the most comprehensively represented with only one country missing (Honduras), but half of the South American countries are not represented and there are no samples from the Caribbean. Although an initial DNA barcode reference library for Neotropical mammals has been established, there are obvious taxonomic and geographic areas that need to be surveyed to make it broadly applicable for species identification and discovery. Nevertheless, preliminary results indicate an underestimation of approximately one-third of the currently recognized species of mammals in the Neotropics, affirming it as a region of high biodiversity.
\end{abstract}

Keywords: Caribbean, Central America, Cytochrome oxidase subunit I (COI), Mammalian biodiversity, Mexico, South America.

\section{INTRODUCTION}

There are 1,692 species of mammals currently recognized as occurring in the Neotropical region $[1,2]$, which is broadly defined as including Mexico, Central America, the Caribbean Islands, and South America. This represents more than $30 \%$ of the total global mammalian biodiversity of 5,498 species $[1,2]$. In contrast, the Neotropics account for less than $15 \%$ of the approximately 150 million $\mathrm{km}^{2}$ of land in the world. Furthermore, the lowland tropical rainforest of western Amazonia has the highest sympatric mammalian diversity on earth and is estimated to be approximately 215 species at any given site [3]. However, the rate of new species discovery is increasing and over 300 species of mammals are expected to be described over the next decade [2]. Many of these are morphologically cryptic species which will be recognized based on genetic analysis of DNA sequence variation [4]. A challenge of taxonomy will be the ability to effectively and efficiently identify and discover this increasing biodiversity.

DNA barcoding has been proposed as an identification system for aiding taxonomic research based on a short standardized fragment of approximately 650 base pairs (bp) of the cytochrome oxidase subunit I (COI) gene region from the mitochondrial genome [5]. This approach has been found

*Address correspondence to this author at the Department of Natural History, Royal Ontario Museum, 100 Queen's Park, Toronto, Ontario M5S 2C6, Canada; Tel: 1-416-586-5771; Fax: 1-416-586-5771;

E-mail: burtonl@ rom.on.ca useful for the diagnosis of closely related species in most animal phyla, including chordates [6]. There have only been a few studies assessing the utility of DNA barcodes for identifying mammalian species but they have focused on a limited taxonomic or geographic scope: primates [7, 8], bats of Guyana [9], and small mammals at Bakhuis, Suriname [10].

The Biodiversity Institute of Ontario (BIO) at the University of Guelph, with its associated molecular sequencing facility at the Canadian Centre for DNA Barcoding (CCDB) and online workbench Barcode of Life Data (BOLD) Systems, established an institutional collaboration with the Royal Ontario Museum (ROM) in 2005 to barcode the tissue collections in the Department of Natural History. A specific collaboration focused on the barcoding of approximately 20,000 tissue samples with museum voucher specimens in the taxonomically and geographically wide-ranging mammal collections at the ROM. This research initiative will give unprecedented insight into genetic variation and molecular evolution of the COI gene and its biological utility within a major class of vertebrates. Preliminary studies have confirmed the effectiveness of DNA barcoding in highly diverse tropical regions by discriminating 87 species of bats from Guyana, which were initially identified by traditional morphological characters [9]. Another study developed field and lab protocols for efficient high-throughput sequencing by subsampling specimens on archival filter paper, which facilitated the species verification in an environmental assessment of the small mammal community structure at Bakhuis, Suriname [10]. 
At present, the sequences from the ROM tissue collections comprise the bulk of the Mammalia Barcode of Life (http://mammaliabol.org) initiative to establish a COI reference database. The objectives of this paper are to review the taxonomic and geographic representation of barcodes from Neotropical mammalian species on the BOLD System (www.barcodinglife.org). This zoogeographic region has been a primary area of research interest in the biodiversity and evolution of mammals, and represents the majority of tissue samples at the ROM. I summarize patterns of sequence diversity for several examples of mammals with varying levels of species representation, distributional range, and sample size to investigate the capabilities and limits of DNA barcoding for species identification and discovery in the Neotropics.

\section{MATERIALS AND METHODOLOGY}

According to the most recent summaries [1,2], there are 1,692 species of mammals that occur in the Neotropics. In addition, 9 more species are included based on recent discovery (Peropteryx pallidoptera [13], an undescribed species of Molossus [14], Marmosa waterhousei [RS Voss, pers. comm.], and Neacomys sp. [MD Engstrom, pers. comm.]), and revised taxonomy (Artibeus bogotensis [15], A. intermedius [16], A. planirostris [17], Peromyscus nudipes [18], and Heteromys goldmani [19]). Consequently, the mammalian biodiversity for this study is based on a total of 1,701 species.

There are 14,577 Neotropical mammal specimens with COI sequences that are currently on BOLD and used in this summary of DNA barcoding. Most of the vouchered specimens $(14,355)$ are deposited at the ROM and the remaining are associated with the tissue collections of Francois Catzeflis at Université de Montpellier that have voucher specimens deposited at the Université de Montpellier, Texas A\&M University, Geneva Natural History Museum, and Paris Museum National d'Histoire Naturelle. Tissue samples were originally preserved in liquid nitrogen or $95 \%$ ethanol with some specimens also sub sampled on archival filter paper cards specifically for barcoding purposes [10]. The molecular protocol for DNA extraction, COI amplification, and nucleotide sequencing is detailed in $[9,10]$. Barcodes were initially aligned and sequence divergence within and among taxa were calculated using the online tools available on BOLD [11]. Sequences were further analyzed in MEGA version 4 [12] based on a neighbor-joining tree of Kimura 2paramater distances with branch support values from 500 bootstrap replicates. The underlying concept of DNA barcoding is that there is more sequence divergence among species than within species. This molecular approach is a useful tool for species identification and discovery in conjunction with taxonomic expertise in applying the appropriate scientific names to clades on the tree. Situations where multiple currently recognized species are referable to the same clade or a species has multiple divergent clades would indicate groups that need systematic attention.

\section{RESULTS}

Almost 20\% (317 species) of mammals of the Neotropics has been DNA barcoded on BOLD (Table 1). This includes
11 of the 15 orders found in the Neotropics with the 4 orders missing (Cetacea, Microbiotheria, Paucituberculata, and Sirenia) representing only 18 species. Nearly $50 \%$ of the bat species (167 of 345) have been barcoded but only 3\% (4 of 129) of the primate species (Ateles paniscus, Cebus apella, Pithecia pithecia, and Saimiri sciureus) have been done (Fig. 1). Rodents are the most diverse order in the Neotropics, of which $12 \%$ of the species have been barcoded (106 of 898). Almost 23\% (21 of 93) of the opossum species have been done. Shrews are another diverse order but only $5 \%$ (3 of 65) of the species have been barcoded. The remaining 5 orders account for relatively few species, of which only a few have been barcoded.

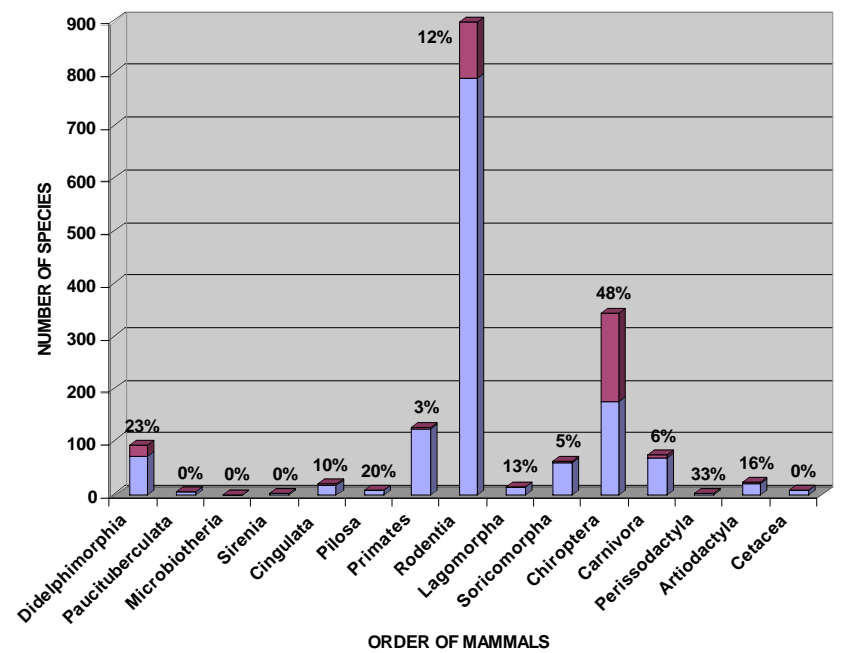

Fig. (1). Histogram of number of species barcoded (purple-top) and number of species not yet barcoded (blue-bottom) for each of the 15 Neotropical orders of mammals. Number of species barcoded is above each bar.

There are DNA barcodes of mammal species from 13 Neotropical countries. In terms of geographic coverage, Middle America (Mexico and Central America) is the most comprehensively represented with only one country, Honduras, missing (Fig. 2). Half of the countries from South America have not been sampled and there are no DNA barcodes of mammals from the Caribbean. In addition, the geographic coverage is uneven with most of southern South America, Amazonia, and the Andes not sampled. There is further sampling bias with almost half of the 14,577 specimens from Guyana (Fig. 3). There are 8 Neotropical mammal orders that have a combination of poor taxonomic and geographic coverage, and low sample size (34 sequences) on BOLD. Nonetheless, the 8 species with multiple samples have < $3 \%$ intraspecific sequence divergence (Table 2) and are each monophyletic with $99 \%$ bootstrap support (Fig. 4). The 5 species pairs within genera are separated by $>10 \%$ sequence divergence and are each monophyletic with $99 \%$ bootstrap support. The 3 families with multiple genera have sequence divergences $>20 \%$ but only 2 form monophyletic clades, each of which are also poorly supported. Of the 3 orders with multiple families, only the Primates is monophyletic and well-supported (99\%). 


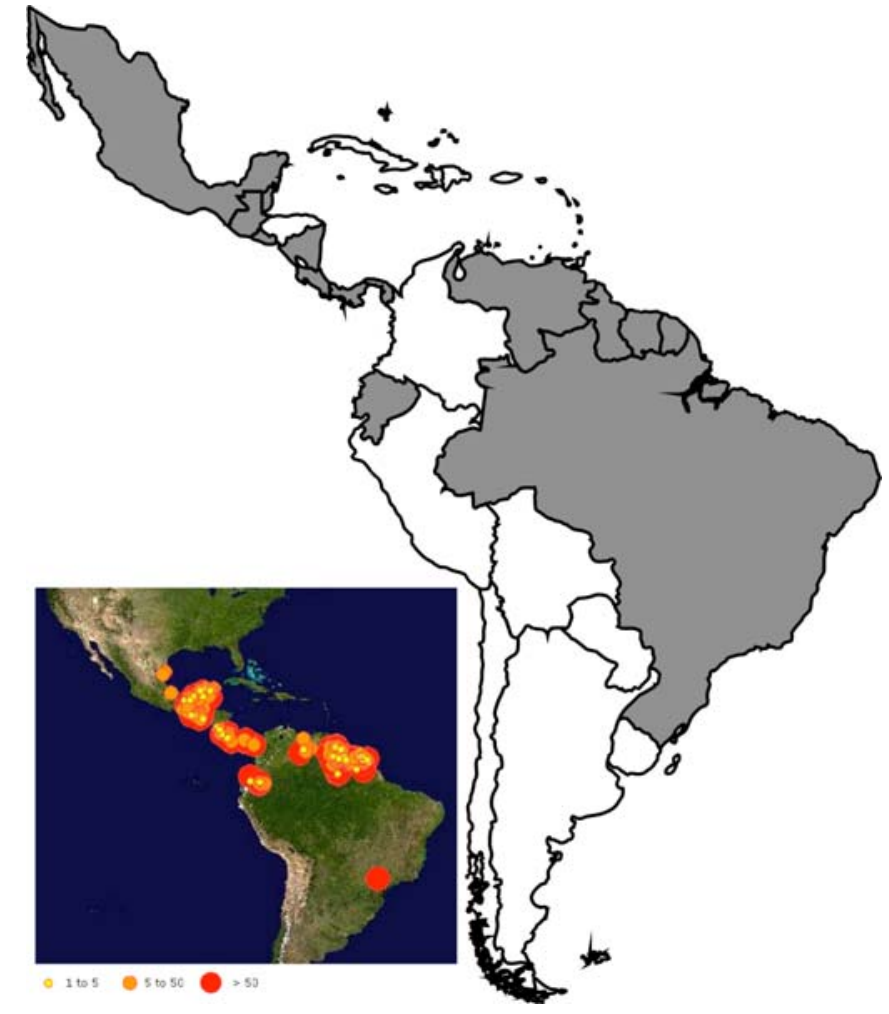

Fig. (2). Map of the Neotropics with countries gray-shaded that have DNA barcodes of mammalian species. Inset map details the distribution of specimen sampling.

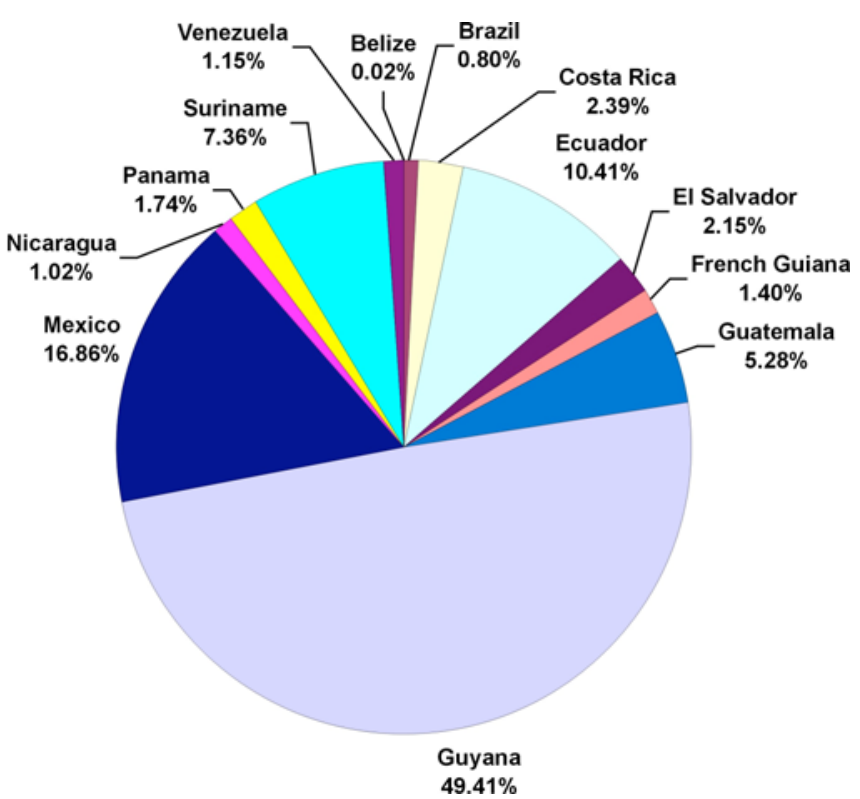

Fig. (3). Percentage of the 14,577 specimens barcoded for each of the 13 Neotropical countries sampled.

The common opossums (order Didelphimorphia), which are all in the family Didelphidae, have better taxonomic coverage and larger sample size with nearly $23 \%$ of the species diversity represented by 240 barcodes (Table 1). Of the 22 species barcoded (1 species is unidentified), 12 form wellsupported (70\%) monophyletic clades (Fig. 5). However, 3 species (Didelphis marsupialis, Marmosa demerarae, and

Table 1. Neotropical Orders of Mammals and the Proportion of Species that have been DNA Barcoded for the COI Mitochondrial Gene Region

\begin{tabular}{|c|c|c|c|}
\hline Artiodactyla & 25 & 4 & $16 \%$ \\
\hline Cetacea & 9 & 0 & $0 \%$ \\
\hline Chiroptera & 345 & 167 & $48 \%$ \\
\hline Didelphimorphia & 93 & 21 & $23 \%$ \\
\hline Lagomorpha & 16 & 2 & $13 \%$ \\
\hline Microbiotheria & 1 & 0 & $0 \%$ \\
\hline Primates & 129 & 4 & $3 \%$ \\
\hline Rodentia & 898 & 106 & $12 \%$ \\
\hline Sirenia & 2 & 0 & $0 \%$ \\
\hline Soricomorpha & 65 & 3 & $5 \%$ \\
\hline Total & 1701 & 317 & $19 \%$ \\
\hline
\end{tabular}


Philander opossum) are paraphyletic. In addition, 5 taxa (Marmosops invictus, Marmosa mexicana, Metachirus nudicaudatus, Monodelphis brevicaudata, and Philander andersoni) exhibit high levels of intraspecific sequence divergence (3-12\%; Table 2). In contrast, interspecific sequence divergence within genus is relatively low $(<3 \%)$ between Didelphis imperfecta and D. pernigra. Intergeneric sequence divergence within Didelphidae is $>10 \%$ and higher level relationships are poorly resolved with low support.

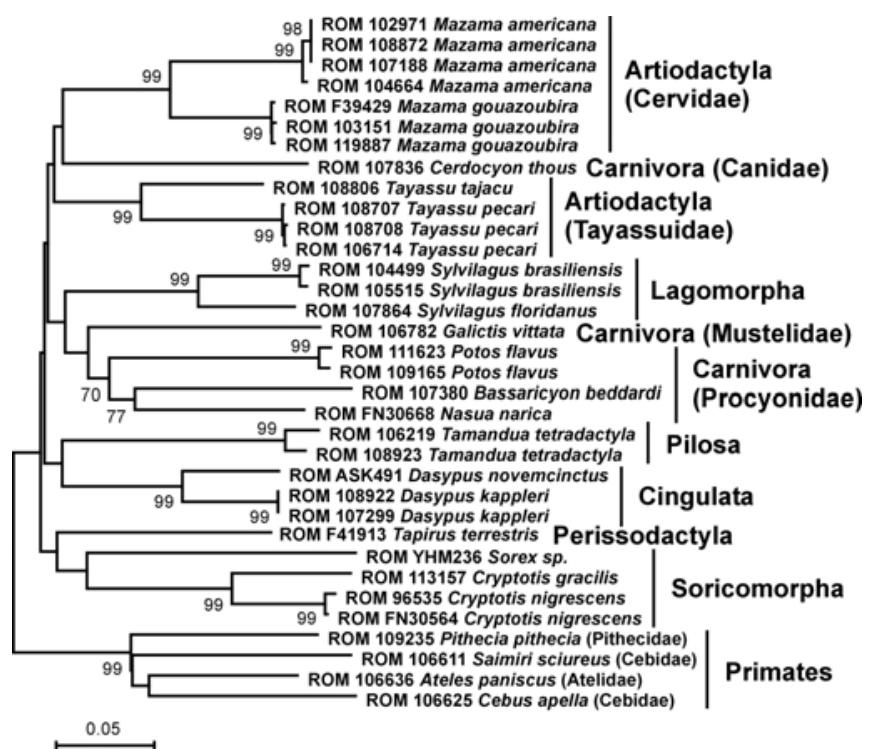

Fig. (4). Neighbor-joining tree based on Kimura 2-parameter model of COI sequences for 8 Neotropical orders of mammals on the Barcode of Life Data (BOLD) system. Branch support values $>70 \%$ from 500 bootstrap replications are indicated.

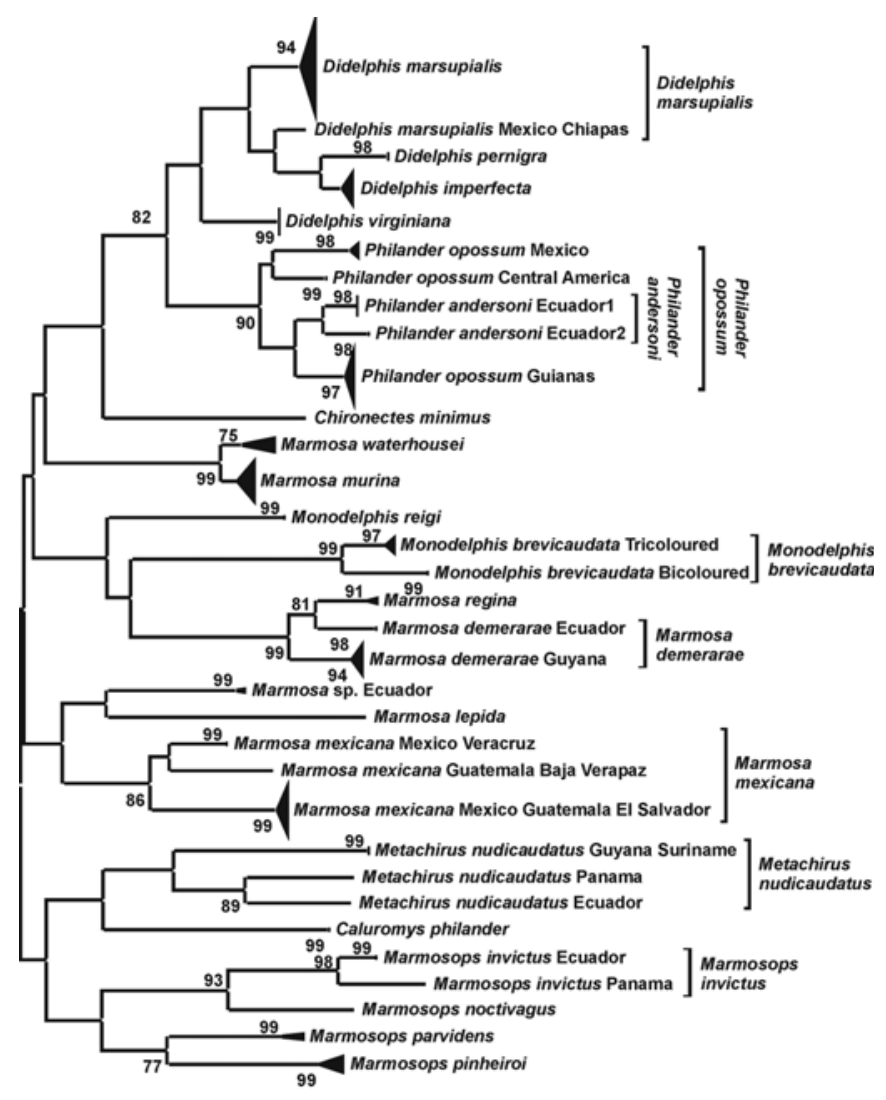

$\stackrel{0.02}{\longmapsto}$

Fig. (5). Neighbor-joining tree based on Kimura 2-parameter model of COI sequences for common opossums (order Didelphimorphia) on the Barcode of Life Data (BOLD) system. Branch support values $>70 \%$ from 500 bootstrap replications are indicated.

Table 2. Four Examples at Various Levels of Taxonomic Rank Summarizing Genetic Distance (Minimum, mean, and Maximum Values with Standard Error) Within Species, Genus, and Family. The Sample Size, Number of Taxa, and Comparisons are Also Summarized

\begin{tabular}{|l|c|c|c|c|c|c|c|c|}
\hline \multicolumn{1}{|c|}{ Rank } & Within & $\mathbf{n}$ & Taxa & Comp. & Min. & Mean & Max. & SE \\
\hline \hline Orders (8 misc.) & Species & 20 & 8 & 17 & 0 & 0.519 & 2.981 & 0.166 \\
\hline & Genus & 24 & 7 & 21 & 10.155 & 12.258 & 13.744 & 0.252 \\
\hline & Family & 29 & 8 & 9 & 20.491 & 22.763 & 25.662 & 0.597 \\
\hline Didelphimorphia & Species & 232 & 18 & 2608 & 0 & 1.432 & 12.01 & 0.044 \\
\hline & Genus & 235 & 8 & 3261 & 2.823 & 9.297 & 20.187 & 0.085 \\
\hline Diclidurini & Family & 236 & 1 & 21846 & 10.486 & 18.467 & 25.759 & 0.022 \\
\hline & Species & 416 & 15 & 16750 & 0 & 1.617 & 9.986 & 0.02 \\
\hline & Genus & 417 & 8 & 7385 & 5.142 & 15.838 & 22.4 & 0.02 \\
\hline Echimyidae & Family & 417 & 1 & 62574 & 17.059 & 22.204 & 30.976 & 0.009 \\
\hline & Species & 510 & 9 & 33194 & 0 & 1.239 & 11.516 & 0.012 \\
\hline & Genus & 513 & 5 & 80638 & 8.473 & 12.819 & 18.731 & 0.006 \\
\hline & Family & 513 & 1 & 17496 & 14.735 & 18.357 & 22.13 & 0.008 \\
\hline
\end{tabular}


Within bats (order Chiroptera), New World emballonurids (tribe Diclidurini) have relatively good taxonomic representation (16 of 22 species) with 418 barcodes. All species form well-supported monophyletic clades, except for Peropteryx macrotis which is paraphyletic in relation to P. kappleri and P. trinitatis (Fig. 6). Three species (Cormura brevirostris, Cyttarops alecto, and Saccopteryx bilineata) have high levels of within species sequence divergence (5-10\%; Table 2). Basal relationships are poorly resolved and not well supported.

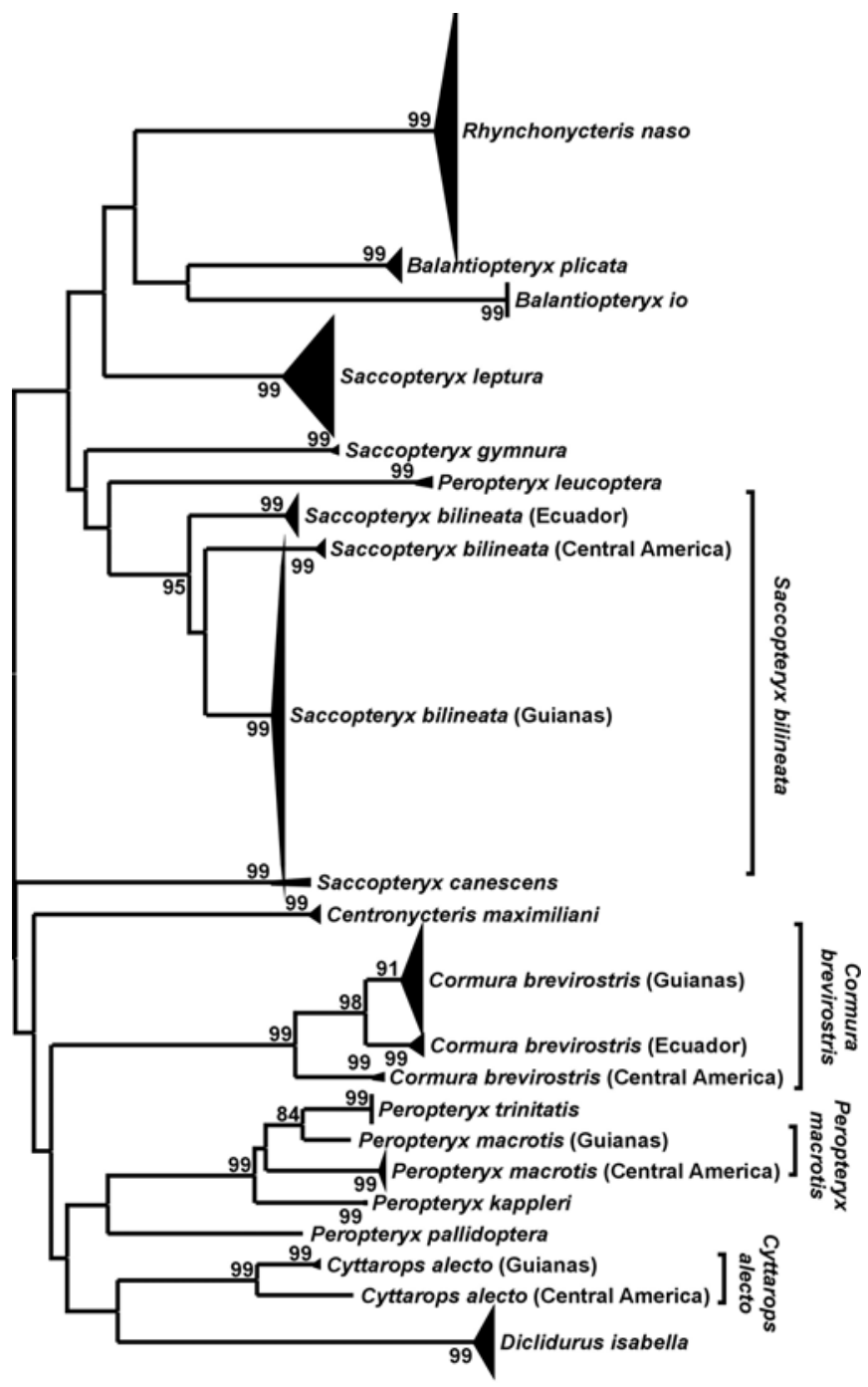
$\overrightarrow{0.02}$

Fig. (6). Neighbor-joining tree based on Kimura 2-parameter model of COI sequences for New World emballonurid bats (tribe Diclidurini) on the Barcode of Life Data (BOLD) system. Branch support values $>70 \%$ from 500 bootstrap replications are indicated.

For rodents (order Rodentia), there are 11 of 90 species of spiny rats (family Echimyidae) represented by 511 barcodes. All species are monophyletic and well-supported (> $87 \%$ ) clades (Fig. 7). Echimyid rodents exhibit levels of high sequence divergence (>6\%; Table 2) within 3 species (Makalata didelphoides, Mesomys hispidus, and Proechimys guyannensis). Interspecific sequence divergence within genera is high (> $8 \%$ ) with monophyletic and well-supported (> $90 \%$ ) clades, except for Echimys.

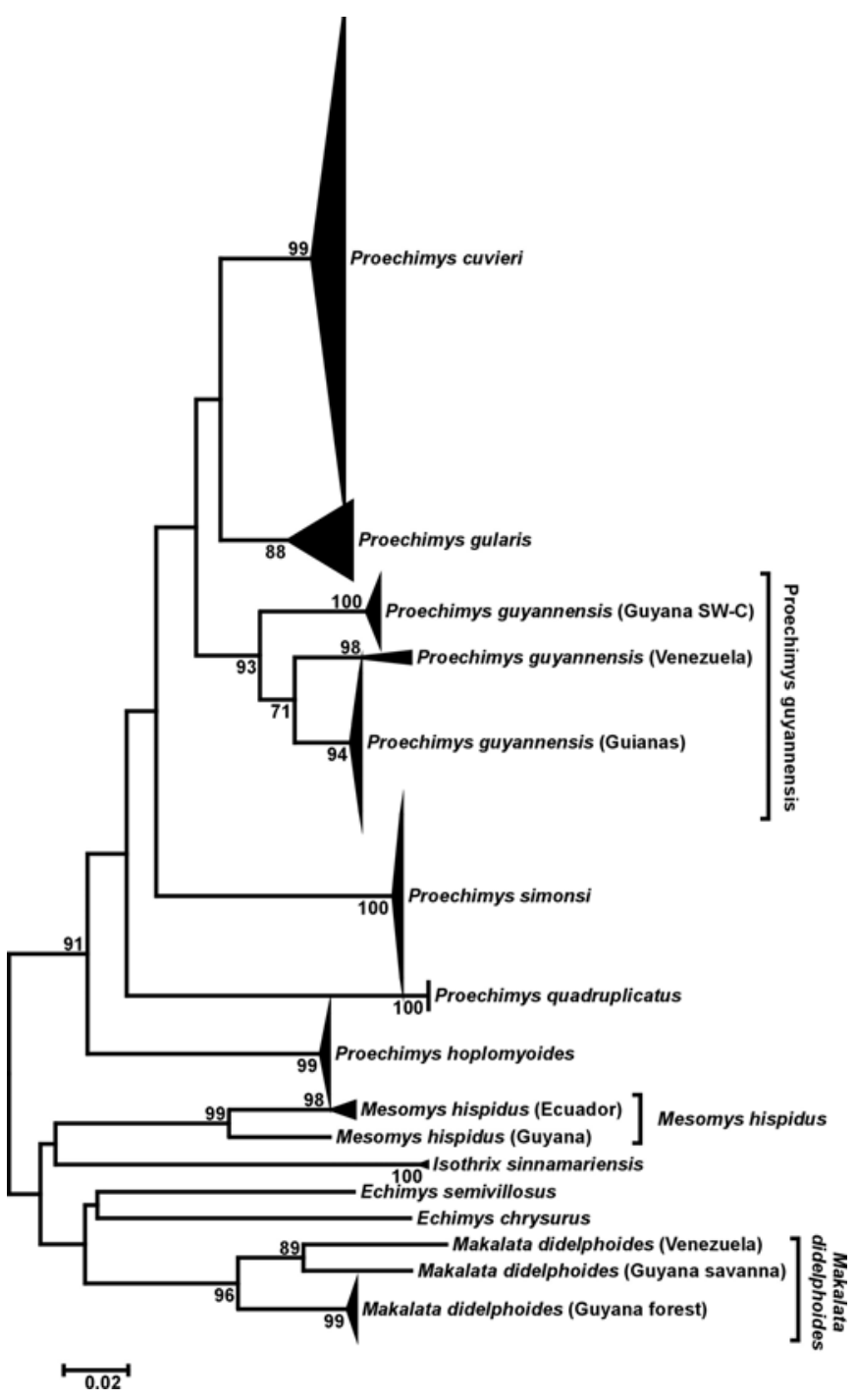

Fig. (7). Neighbor-joining tree based on Kimura 2-parameter model of COI sequences for spiny rats (family Echimyidae) on the Barcode of Life Data (BOLD) system. Branch support values $>70 \%$ from 500 bootstrap replications are indicated.

\section{DISCUSSION}

Although taxonomic and geographic coverage is far from complete, comparisons reported herein can be made with the most comprehensive study to date using mammalian DNA barcodes, which was based on the 87 bat species from Guyana [9]. For 81 of those species, there was low intraspecific variation (mean $=0.60 \%)$ coupled with high intrageneric variation (mean $=7.80 \%$ ). The barcoding gap was even greater between the mean intraspecific $(0.52 \%)$ and intrageneric $(12.26 \%)$ variation for the 8 miscellaneous orders of Neotropical mammals representing 22 species summarized in Table 2. Not surprisingly, this indicates that there is no difficulty in distinguishing these taxa. However, the mean intraspecific variation for the other 3 taxa studies herein was over twice as high (ranging from $1.24 \%$ for Echimyidae to $1.62 \%$ for Diclidurini) with maximum values of 9.99$12.01 \%$ that are comparable to intrageneric values for bats from Guyana and miscellaneous orders of Neotropical mammals. This suggests that more detailed systematic study 
is needed to investigate the high levels of intraspecific variation within the various taxonomic ranks of Didelphimorphia, Diclidurini, and Echimyidae.

Three species of didelphid opossums surveyed were paraphyletic and had high levels of sequence divergence $(>2.6 \%)$ within the currently recognized taxa (Fig. 5). (1) The paraphyly of Didelphis marsupialis, however, is poorly supported $(<50 \%)$ and probably represents a methodological artifact of the tree-building algorithm. In this particular case, one unique sample from Chiapas, Mexico was morphologically identified as $D$. marsupialis but was divergent by up to $2.67 \%$ from samples of this species from other localities. (2) Philander opossum has intraspecific sequence divergence ranging up to $6 \%$ but its paraphyly is also poorly supported $(<53 \%)$. However, there is phylogeographic structuring in the COI data corroborating an earlier study using cytochrome $b$ data that assigned eastern Amazonia including the Guianas to $P$. o. opossum, western Amazonia to P. o. canus, and Central America to $P$. o. fuscogriseus [23]. It was further suggested that these taxa may represent valid species [20], which warrants further analysis with the recent description of 2 new species in Venezuela and Colombia that are distinct from $P$. opossum [21]. (3) In contrast, there are 2 distinct lineages within Marmosa demerarae that have intraspecific sequence divergence up to $9 \%$ and the paraphyly with $M$. regina is well supported (>80\%). Marmosa demerarae was not known from Ecuador prior to this study [27, 28]. This lineage is considered a distinct species from the nominal lineage from Guyana and is awaiting taxonomic revision (RS Voss, pers. comm.).

There are 5 species of didelphids that each form monophyletic clades composed of 2 or 3 divergent lineages within. (1) Monodelphis brevicaudata has intraspecific sequence divergence $>6 \%$ between an allopatrically distributed bicoloured form from northeastern Venezuela and northwestern Guyana, and a tricoloured form from the remainder of the Guiana Shield north of the Amazon River. The bicoloured form corresponds to the nominal taxon $M$. $b$. brevicaudata but the extent of variation and systematic relationships with tricoloured forms needs more comprehensive geographic sampling to adequately resolve the taxonomy [22, 23]. (2) There is almost $10 \%$ intraspecific sequence divergence among 3 lineages of Marmosa mexicana in Mexico and Central America. However, there needs to be more systematic study of other named forms such as M. robinsoni to get a better understanding of the phylogenetic relationships in this group $[24,25]$. (3) There is up to $12 \%$ sequence divergence within Metachirus nudicaudatus among 3 allopatrically distributed lineages from Central America, northwestern Amazonia, and the Guianas. Names referable to these lineages are M. n. colombianus, M. n. tschudii, and M. n. nudicaudatus, respectively [26]. Three additional divergent lineages were found in eastern Amazonia (which was distinct from the Guianas), southwestern Amazonia (M. n. modestus) and the Atlantic Forest (M. n. myosuros) that suggest the presence of several cryptic species [26, 27]. There is high sequence divergence (12\%) between populations from the Guianas and eastern Amazonia that were grouped under M. $n$. nudicaudatus [26] but the latter population should also be recognized as a distinct taxon that does not appear to have a name referable to it. (4) Marmosops invictus has high levels of intras- pecific sequence divergence $(3.5 \%)$ and phylogeographic structuring between 2 lineages from Panama and eastern Ecuador. This species was previously known from only Panama [28] and this lineage from Amazonian Ecuador may represent a new undescribed species. (5) In contrast, Philander andersoni has intraspecific sequence divergence $>5 \%$ for individuals from the same locality in eastern Ecuador. This potentially cryptic species scenario also warrants further systematic study.

In total, there are possibly 10 additional taxa of opossums that may warrant valid species recognition. This represents almost a 50\% increase in diversity from the original 22 species barcoded for the order Didelphimorphia. Although some of these taxonomic distinctions were noted earlier by other researchers, the divergence within Marmosops invictus and Philander andersoni were newly detected by DNA barcoding analysis.

Within the New World emballonurid bats (tribe Diclidurini), 4 of the 16 species have high levels of intraspecifc sequence divergence ( $>5 \%)$ with strong phylogeographic structuring (Fig. 6). However, only one of these species (Peropteryx macrotis) does not form a well supported (>94\%) monophyletic clade because of divergent Central and South America populations. (1) There are 3 distinct lineages in Saccopteryx bilineata from Central America, eastern Ecuador, and the Guianas with sequence divergence ranging up to $10 \%$. These 3 lineages were recovered by an earlier phylogenetic analysis of cytochrome $b$ but there was no phylogeographic structure recovered by 3 gene trees from unlinked loci representing different nuclear transmission pathways (autosomal, X and Y sex chromosomes) [29]. Two subspecies were recognized with the holotype of the nominal form, S. $b$. bilineata, from Suriname in the Guianas and S. $b$. centralis from Central America [30]. There is no name associated with the western Amazonian population from Ecuador. (2) Similarly, there are 3 lineages in Cormura brevirostris from Central America, eastern Ecuador and the Guianas with sequence divergence ranging up to $8.5 \%$. The earlier phylogenetic analysis using loci from the 4 different genetic transmission pathways had incomplete geographic sampling, so it could not completely corroborate the DNA barcoding topology [29]. No subspecies are currently recognized for this species [30, 31]. (3) Cyttarops alecto has 2 distinct lineages from the Guianas and Central America with sequence divergence ranging up to almost $6 \%$. These 2 lineages were recovered by an earlier phylogenetic analysis of cytochrome $b$ but there was also incomplete geographic sampling in loci from the 3 different nuclear genetic transmission pathways [29]. There are no subspecies recognized for this species [30, 31]. (4) Peropteryx macrotis is paraphyletic in relation to $P$. trinitatis with 2 lineages from Central America and Suriname in the Guianas having sequence divergences ranging up to $8 \%$. The previous phylogenetic analysis of cytochrome $b$ data recovered 3 divergent lineages, including Central America and 2 distinct lineages from the Guianas [29]. However, there was incomplete geographic sampling in loci from the 3 nuclear genetic transmission pathways to corroborate deep splits within $P$. macrotis and phylogenetic relationships with $P$. trinitatis, and $P$. kappleri. There are no subspecies currently recognized from the continental mainland for P. macrotis [30, 31]. In total for New World embal- 
lonurids, there are 6 unrecognized lineages with phylogeographic structure and deep divergence from the 16 recognized species in the DNA barcoding data set.

Echimyid rodents exhibit similar levels of high sequence divergence up to $11.5 \%$ within 3 of the 11 species that were barcoded; however, all taxa were monophyletic (Fig. 7). Unlike the opossums and sheath-tailed bats, these spiny rats are not widely distributed except for Mesomys hispidus. (1) Mesomys hispidus has 2 lineages with sequence divergence reaching almost $8 \%$ between populations from eastern Ecuador and Guyana. An additional 3 lineages were found in an earlier systematic analysis, including a French Guiana and central Amazon clade (excluding Guyana) that included the holotype, but a single species was retained for this group pending more comprehensive studies to be completed [32]. (2) Makalata didelphoides has 3 lineages from the savanna in south-central Venezuela, savanna in southwestern Guyana, and forest in central Guyana. Sequence divergence ranged up to almost $12 \%$. In an earlier study in Brazil, there were 2 additional populations from eastern and southern Amazonia that had similar sequence divergence [26]. However, this is the first report of deep splits within populations of $M$. didelphoides from the Guianas. (3) There is up to $10 \%$ sequence divergence among 3 lineages of Proechimys guyannensis from the Llanos savanna and adjacent forest south of the Orinoco in Venezuela, Rupununi savanna and adjacent forest in southwestern Guyana, and primarily forest (but including the southern Rupununi savanna) in the remainder of the Guianas. These populations are referable to $P$. $g$. cherriei, $P$. g. vacillator, and $P$. g. guyannensis, respectively [26]. However, there are other taxa of $P$. guyannensis in the Guiana Shield may also represent distinct species [26, 33]. Of the 11 species of echimyid rodents reported herein, there are potentially 6 taxa that warrant species recognition.

DNA barcoding is not only useful for the identification and discovery of species, it is also useful for approximating times of divergence. For example, genetic distance between species within genera is relatively low $(2.8 \%)$ for Didelphis imperfecta and D. pernigra. This suggests a relatively recent split from a common ancestor, however, incorporating fossil records as calibration points in a multi-loci relaxed-clock molecular dating analysis would be the most informative approach to detailing historical lineage splitting events.

\section{CONCLUSION}

Approximately $80 \%$ of Neotropical mammals still need to be sequenced to achieve a complete COI reference database for efficient species identification and discovery. Taxonomic priority groups for DNA barcoding are rodents, primates, carnivores, and shrews. Geographic priority areas are the Caribbean and southern South America. Nonetheless, almost $95 \%$ of the currently recognized species in the 4 taxonomic groups analyzed herein were discretely identifiable by monophyletic clades in a neighbor-joining tree. However, unrecognized species of Neotropical mammals may represent one-third to one-half of the currently known biodiversity. DNA barcoding is a useful and effective tool to assist taxonomists in discovering cryptic and unrecognized species that warrant further biological investigation from an evolutionary biology perspective.

\section{ACKNOWLEDGEMENTS}

Thanks to Alex Borisenko, Natalia Ivanova, Beth Clare, Miranda Elliott, and Paul Hebert at the Biodiversity Institute of Ontario and the Canadian Centre for DNA Barcoding (BIO) at the University of Guelph for continued support and assistance during all aspects of this sequencing project. Collection management and curation of the voucher specimens and tissue samples were ably provided by Susan Woodward, Jim Borack, and Liliane Lortie in mammalogy at the Royal Ontario Musuem (ROM). Laboratory analyses were supported by grants to Paul Hebert from the Gordon and Betty Moore Foundation, Genome Canada through the Ontario Genomics Institute, Canada Foundation for Innovation, Ontario Innovation Trust, and Natural Sciences and Engineering Research Council. Primary support of fieldwork and research on Neotropical mammals associated with the collection of voucher specimens and tissue samples have been generously provided over the past 2 decades by the Department of Natural History and the ROM Governors to Mark Engstrom and me. Research and export permits were kindly authorized by government agencies in Mexico, Belize, Guatemala, El Salvador, Nicaragua, Costa Rica, Panama, Ecuador, Venezuela, Guyana, Suriname, French Guiana, and Brazil. I thank Judith Eger, Francois Catzeflis, and Sergio Solari for critically reviewing earlier drafts of this paper.

\section{CONFLICT OF INTEREST}

None declared.

\section{REFERENCES}

[1] Wilson DE, Reeder DM, Eds. Mammal Species of the World: A Taxonomic and Geographic Reference. 3rd ed. Baltimore: Johns Hopkins University Press 2005.

[2] Reeder DM, Helgen KM, Wilson DE. Global trends and biases in new mammal species discoveries. Occ Pap Mus Texas Tech Univ 2007; 269: 1-35.

[3] Voss RS, Emmons LH. Mammalian diversity in Neotropical lowland rainforests: a preliminary assessment. Bull Amer Mus Nat Hist 1996; 230: 1-115.

[4] Baker RJ, Bradley RD. Speciation in mammals and the genetic species concept. J Mammal 2006; 87: 643-62.

[5] Hebert PDN, Cywinska A, Ball SL, deWaard JR. Biological identifications through DNA barcodes. Proc Roy Soc Lond Ser B Biol Sci 2003; 270: 313-21.

[6] Hebert PDN, Ratnasingham S, deWaard JR. Barcoding animal life: cytochrome c oxidase subunit 1 divergences among closely related species. Proc Roy Soc Lond Ser B Biol Sci 2003; 270: S596-S9.

[7] Lorenz JG, Jackson WE, Beck JC, Hanner R. The problems and promise of DNA barcodes for species diagnosis of primate biomaterials. Phil Trans Roy Soc Lond Ser B, Biol Sci 2005; 360: 186977.

[8] Hajibabaei M, Singer GAC, Hickey DA. Benchmarking DNA barcodes: an assessment using available primate sequences. Genome 2006; 49: 851-4.

[9] Clare EL, Lim BK, Engstrom MD, Eger JL, Hebert PDN. DNA barcoding of Neotropical bats: species identification and discovery within Guyana. Mol Ecol Notes 2007; 7: 184-90.

[10] Borisenko AV, Lim BK, Ivanova NV, Hanner RH, Hebert PDN. DNA barcoding in surveys of small mammal communities: a field study in Suriname. Mol Ecol Resources 2008; 8: 471-9.

[11] Ratnashingham S, Hebert PDN. BOLD: The Barcode of Life Data System (www.barcodinglife.org). Mol Ecol Notes 2007; 7: 355-64.

[12] Tamura K, Dudley J, Nei M, Kumar S. MEGA4: Molecular Evolutionary Genetics Analysis (MEGA) software version 4.0. Mol Biol Evol 2007; 24: 1596-9.

[13] Lim BK, Engstrom MD, Reid FA, Simmons NS, Voss RS, Fleck DW. A new species of Peropteryx (Chiroptera: Emballonuridae) 
from Western Amazonia with comments on phylogenetic relationships within the genus. Amer Mus Novitates 2010; 3686: 1-20.

[14] Lim BK, Engstrom MD. Species diversity of bats (Mammalia: Chiroptera) in Iwokrama Forest, Guyana, and the Guianan subregion: implications for conservation. Biodivers Cons 2001; 10: 61357.

[15] Lim BK, Engstrom MD, Bickham JW, Patton JC. Systematic review of small fruit-eating bats (Artibeus) from the Guianas, and a re-evaluation of $A$. glaucus bogotensis. Acta Chiropterologica 2008; 10: 243-56

[16] Davis WB. Review of the large fruit-eating bats of the Artibeus 'lituratus' complex (Chiroptera: Phyllostomidae) in Middle America. Occ Pap Mus Texas Tech Univ 1984; 93: 1-16.

[17] Lim BK, Engstrom MD, Lee TE, Patton JC, Bickham JW. Molecular differentiation of large species of fruit-eating bats (Artibeus) and phylogenetic relationships based on the cytochrome $b$ gene. Acta Chiropterologica 2004; 6: 1-12.

[18] Rogers DS, Engstrom MD. Evolutionary implications of allozymic variation in tropical Peromyscus of the mexicanus species group. J. Mammal 1992; 72: 55-69.

[19] Rogers DS, Schmidley DJ. Systematics of spiny pocket mice (genus Heteromys) of the desmarestianus species group from México and northern Central America. J Mammal 1982; 63: 375-86.

[20] Patton JL, da Silva MNF. Definition of species of pouched foureyed opossums (Didelphidae, Philander). J Mammal 1997; 78: 90102.

[21] Lew D, Pérez-Hernández R, Ventura J. Two new species of Philander (Didelphimorphia, Didelphidae) from northern South America. J Mammal 2006; 87: 224-37.

[22] Lim BK, Engstrom MD, Patton JC, Bickham JW. Molecular phylogenetics of Reig's short-tailed opossum (Monodelphis reigi) and its distributional range extension into Guyana. Mamm Biol 2010; 75: 287-93

[23] Voss RS, Lunde DP, Simmons NB. The mammals of Paracou, French Guiana: a neotropical lowland rainforest fauna. Part 2. Nonvolant species. Bull Amer Mus Nat Hist 2001; 263: 1-236.
[24] Engstrom MD, Lim BK, Reid FA. Two new small mammals new to the fauna of El Salvador. Southwestern Nat 1994; 39: 281-283.

[25] Engstrom MD, Reid FA, Lim BK. New records of two small mammals from Guatemala. Southwestern Nat 1993; 38: 80-2.

[26] Patton JL, Da Silva MNF, Malcolm JR. Mammals of the Rio Juruá and the evolutionary and ecological diversification of Amazônia Bull Amer Mus Nat Hist 2000; 244: 1-306.

[27] Gardner AL, Dagosto, M. Tribe Metachirini Reig, Kirsch, and Marshall, 1985. In: Gardner AL, Ed. Mammals of South America. vol. 1. Marsupials, xenarthrans, shrews, and bats. Chicago: University of Chicago Press 2008; pp. 35-9.

[28] Gardner AL. Order Didelphimorphia. In: Wilson DE, Reeder DM, Eds. Mammal species of the world: a taxonomic and geographic reference. 3rd ed. Baltimore: Johns Hopkins University Press 2005; pp. 3-18.

[29] Lim BK, Engstrom MD, Bickham JW, Patton JC. Molecular phylogeny of New World emballonurid bats (Tribe Diclidurini) based on loci from the four genetic transmission systems in mammals. Biol J Linn Soc 2008; 93: 189-209.

[30] Hood C, Gardner AL. Family Emballonuridae Gervais, 1856. In: Gardner AL, Ed. Mammals of South America. vol. 1. Marsupials, xenarthrans, shrews, and bats. Chicago: University of Chicago Press 2008; pp. 188-207.

[31] Simmons NB. Order Chiroptera. In: Wilson DE, Reeder DM, Eds. Mammal species of the world: a taxonomic and geographic reference. 3rd ed. Baltimore: Johns Hopkins University Press 2005; pp. 312-529.

[32] Orlando L, Mauffrey JF, Cuisin J, Patton JL, Hänni C, Catzeflis F. Napoleon Bonaparte and the fate of an Amazonian rat: new data on the taxonomy of Mesomys hispidus (Rodentia: Echimyidae). Mol Phylogenet Evol 2003; 27: 113-20.

[33] Woods CA, Kilpatrick CW. Infraorder Hystricognathi Brandt, 1855. In: Wilson DE, Reeder DM, Eds. Mammal species of the world: a taxonomic and geographic reference. 3rd ed. Baltimore: Johns Hopkins University Press 2005; pp. 1538-600.

(C) Burton K. Lim; Licensee Bentham Open.

This is an open access article licensed under the terms of the Creative Commons Attribution Non-Commercial License (http://creativecommons.org/licenses/by-nc/3.0/) which permits unrestricted, non-commercial use, distribution and reproduction in any medium, provided the work is properly cited. 